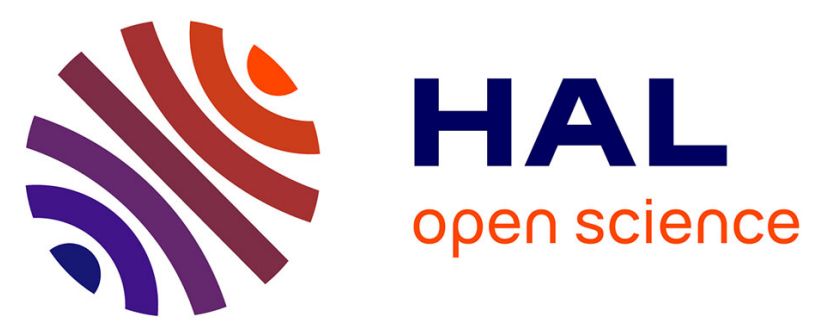

\title{
Equine alphaherpesviruses (EHV-1 and EHV-4) differ in their efficiency to infect mononuclear cells during early steps of infection in nasal mucosal explants
}

Annelies P. Vandekerckhove, S. Glorieux, A.C. Gryspeerdt, L. Steukers, J. van Doorsselaere, N. Osterrieder, G.R. van de Walle, H.J. Nauwynck

\section{To cite this version:}

Annelies P. Vandekerckhove, S. Glorieux, A.C. Gryspeerdt, L. Steukers, J. van Doorsselaere, et al.. Equine alphaherpesviruses (EHV-1 and EHV-4) differ in their efficiency to infect mononuclear cells during early steps of infection in nasal mucosal explants. Veterinary Microbiology, 2011, 152 (1-2), pp.21. 10.1016/j.vetmic.2011.03.038 . hal-00719074

\section{HAL Id: hal-00719074 \\ https://hal.science/hal-00719074}

Submitted on 19 Jul 2012

HAL is a multi-disciplinary open access archive for the deposit and dissemination of scientific research documents, whether they are published or not. The documents may come from teaching and research institutions in France or abroad, or from public or private research centers.
L'archive ouverte pluridisciplinaire HAL, est destinée au dépôt et à la diffusion de documents scientifiques de niveau recherche, publiés ou non, émanant des établissements d'enseignement et de recherche français ou étrangers, des laboratoires publics ou privés. 


\section{Accepted Manuscript}

Title: Equine alphaherpesviruses (EHV-1 and EHV-4) differ in their efficiency to infect mononuclear cells during early steps of infection in nasal mucosal explants

Authors: Annelies P. Vandekerckhove, S. Glorieux, A.C.

Gryspeerdt, L. Steukers, J. Van Doorsselaere, N. Osterrieder,

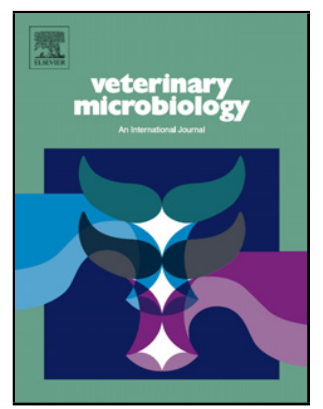
G.R. Van de Walle, H.J. Nauwynck

PII:

DOI:

S0378-1135(11)00215-X

Reference: doi:10.1016/j.vetmic.2011.03.038

To appear in: $\quad$ VETMIC

Received date: 14-1-2011

Revised date: 29-3-2011

Accepted date: $\quad 31-3-2011$

Please cite this article as: Vandekerckhove, A.P., Glorieux, S., Gryspeerdt, A.C., Steukers, L., Van Doorsselaere, J., Osterrieder, N., Van de Walle, G.R., Nauwynck, H.J., Equine alphaherpesviruses (EHV-1 and EHV-4) differ in their efficiency to infect mononuclear cells during early steps of infection in nasal mucosal explants, Veterinary Microbiology (2010), doi:10.1016/j.vetmic.2011.03.038

This is a PDF file of an unedited manuscript that has been accepted for publication. As a service to our customers we are providing this early version of the manuscript. The manuscript will undergo copyediting, typesetting, and review of the resulting proof before it is published in its final form. Please note that during the production process errors may be discovered which could affect the content, and all legal disclaimers that apply to the journal pertain. 
1 Equine alphaherpesviruses (EHV-1 and EHV-4) differ in their efficiency to

2 infect mononuclear cells during early steps of infection in nasal mucosal

3

4

5

6

explants

Annelies P. Vandekerckhove ${ }^{\text {a\# }}$, S. Glorieux ${ }^{\mathrm{a}}$, A. C. Gryspeerdt ${ }^{\mathrm{a}}$, L. Steukers ${ }^{\mathrm{a}}$, J. Van Doorsselaere $^{\mathrm{b}}$, N. Osterrieder ${ }^{\mathrm{c}}$, G. R. Van de Walle ${ }^{\mathrm{d} *}$ and H. J. Nauwynck ${ }^{\mathrm{a}}$

${ }^{\mathrm{a}}$ Department of Virology, Parasitology and Immunology, ${ }^{\mathrm{d}}$ Department of Physiology and Biometrics, Faculty of Veterinary Medicine, Ghent University, Salisburylaan 133, B-9820 Merelbeke, Belgium

${ }^{\mathrm{b}}$ KATHO Catholic University College of South-West Flanders, 8800 Roeselare, Belgium ${ }^{\mathrm{c}}$ Institut für Virologie, Freie Universität Berlin, Philippstrasse 13, 10115 Berlin, Germany *shared senior autorship

\#Corresponding author: Annelies Vandekerckhove

Laboratory of Virology, Faculty of Veterinary Medicine, Ghent University

Salisburylaan 133, 9820 Merelbeke, Belgium

Phone: +329264 73 75, Fax: +329264 7495

Email: annelies.vandekerckhove@UGent.be 
27 Equine herpesvirus type $1(\mathrm{EHV}-1)$ replicates extensively in the epithelium of the upper

respiratory tract, after which it can spread throughout the body via a cell-associated viremia in mononuclear leukocytes reaching the pregnant uterus and central nervous system. In a previous study, we were able to mimic the in vivo situation in an in vitro respiratory mucosal explant system. A plaquewise spread of EHV-1 was observed in the epithelial cells, whereas in the connective tissue below the basement membrane (BM), EHV-1-infected mononuclear leukocytes were noticed. Equine herpesvirus type 4 (EHV-4), a close relative of EHV-1, can also cause mild respiratory disease, but a cell-associated viremia in leukocytes is scarce and secondary symptoms are rarely observed. Based on this striking difference in pathogenicity, we aimed to evaluate how EHV-4 behaves in equine mucosal explants. Upon inoculation of equine mucosal explants with the EHV-4 strains VLS 829, EQ 012 and V01-3-13, replication of EHV-4 in epithelial cells was evidenced by the presence of viral plaques in the epithelium. Interestingly, EHV-4-infected mononuclear leukocytes in the connective tissue below the BM were extremely rare and were only present for one of the three strains. The inefficient capacity of EHV-4 to infect mononuclear cells explains in part the rarity of EHV-4-induced viremia, and subsequently, the rarity of EHV-4-induced abortion or EHM.

Key words: EHV-4; hampered spread; basement membrane barrier; mononuclear cells 
At first, the equine alphaherpesviruses equine herpesvirus type 1 (EHV-1) and equine herpesvirus type 4 (EHV-4) were considered as 2 subtypes of the same virus, designated EHV-1 subtype 1 and EHV-1 subtype 2 respectively (Sabine et al., 1981; Studdert et al., 1981). Additional sequence information confirmed that EHV-1 and EHV-4 are actually two closely related, but distinct viruses, with an amino acid (aa) sequence identity ranging between $54.9 \%$ and $96.4 \%$ (Telford et al., 1998). To date, EHV-1 and EHV-4 are both classified as members in the order Herpesvirales, subfamily Alphaherpesvirinae, genus Varicellovirus (Davison et al., 2009).

EHV-1 and EHV-4 are major causative agents of respiratory disease in the horse (Allen and Bryans, 1986; Crabb and Studdert, 1995; Reed and Toribio, 2004). Initial infection starts with replication of the virus in epithelial cells lining the upper respiratory tract (URT). EHV-1 does not only have a tropism for epithelial cells, but also targets mononuclear leukocytes, misusing these cells for viral transportation through the basement membrane (BM) barrier (Kydd et al., 1994; Gryspeerdt et al., 2010). Indeed, we showed in a previous study that EHV-1-induced plaques cannot breach the BM, but that EHV-1 penetrates the deeper tissues of the respiratory tract in a more discrete manner, using migrating individual mononuclear cells as a Trojan horse (Vandekerckhove et al., 2010). Carried by these mononuclear leukocytes, EHV-1 can easily spread through the body via a cell-associated viremia, reaching its target organs, the pregnant uterus and the central nervous system. At these secondary replication sites, EHV-1 replicates in endothelial cells, causing vasculitis, thrombosis and disseminated ischemic necrosis, resulting in abortion and nervous system disorders (Smith et al., 1996; Wilson, 1997; Smith and Borchers; 2001; Reed and Toribio, 2004; Brosnahan and Osterrieder, 2009). In contrast, EHV-4 infection remains mostly restricted to the URT and a cell-associated viremia, following primary replication in the URT is very rare (Patel et al., 1982; van 
72

73

74

75

76

77 isolates.

Maanen, 2002; Patel and Heldens, 2005). What determines this difference in pathogenic potential between EHV-1 and EHV-4 is unknown up till now. Strikingly, pathogenicity seems to be correlated with host cell range. EHV-1 has a broad host range and can replicate in equine, human, mouse, monkey, hamster, rabbit, pig, bovine, canine, feline and even avian cells (Studdert and Blackney, 1979; Trapp et al., 2005), whilst EHV-4 replication seems to be mainly restricted to equine cells. Furthermore, EHV-1 can infect mice and cause respiratory disease while this is not the case for EHV-4 (Awan et al., 1990; Azmi and Field, 1993).

In this study, we aimed to evaluate how EHV-4 interacts with the respiratory mucosa upon inoculation of equine respiratory mucosal explants and we wanted to compare these replication kinetics with those of its close relative, EHV-1.

\section{Materials and Methods}

\subsection{Donor horses}

Material from slaughter horses was used to obtain nasal explants. Horses negative for nasal/ocular discharge and lung pathology were selected. All horses were between 5 and 7 years old, as determined by inspection of dental incisive architecture (Muylle et al., 1996). A complement-dependent seroneutralization (SN)-test was performed on the serum of all horses and EHV-specific antibody titres ranged between 24 and 96. Nasal explants of at least three individual horses were used to evaluate replication kinetics of several EHV-1 and EHV-4 
Three different EHV-4 strains were used in this study. EHV-4 isolate VLS 829 was provided

\subsection{Cultivation of the nasal mucosal explants}

The cultivation of nasal mucosal explants was performed exactly as previously described (Vandekerckhove et al., 2009). In brief, immediately after slaughter, the head was removed from the carcass and longitudinally sawn into 2 equal sections. Tissue from the deep intranasal part of the septum was collected. The tissues were transported on ice in phosphate buffered saline (PBS), supplemented with $1 \mu \mathrm{g} / \mathrm{mL}$ gentamicin (Invitrogen, Paisley, UK), 1 mg/mL streptomycin (Certa, Braine l'Alleud, Belgium), $1000 \mathrm{U} / \mathrm{mL}$ penicillin (Continental Pharma, Puurs, Belgium), $1 \mathrm{mg} / \mathrm{mL}$ kanamycin (Sigma-Aldrich, St. Louis, MO, USA) and 5 $\mu \mathrm{g} / \mathrm{mL}$ fungizone (Bristol-Myers Squibb, New York, USA), to the laboratory. Mucosal explants were stripped from the surface of the different tissues by use of surgical blades (Swann-Morton). The stripped mucosa of each tissue was divided into equal explants of 25 $\mathrm{mm}^{2}$ and placed epithelium upwards on fine-meshed gauze for culture at an air-liquid interface. Only a thin film of serum-free medium (50\% Roswell Park Memorial Institute medium (RPMI, Invitrogen)/50 \% Dulbecco's Modified Eagle Medium (DMEM, Invitrogen) supplemented with $0.3 \mathrm{mg} / \mathrm{mL}$ glutamine (BDH Biochemical, Poole, UK), $1 \mu \mathrm{g} / \mathrm{mL}$ gentamicin (Invitrogen), $0.1 \mathrm{mg} / \mathrm{mL}$ streptomycin (Certa) and $100 \mathrm{U} / \mathrm{mL}$ penicillin (Continental Pharma)) covered the explants, thereby mimicking the air/liquid interface found in the respiratory tract of the living animal. Explants were maintained at $37{ }^{\circ} \mathrm{C}$ in an atmosphere containing $5 \% \mathrm{CO}_{2}$.

\subsection{Virus}

by the Office International d'Epizooties Reference Laboratory (University of Kentucky, Lexington, KY) and was identified as EHV-4 by restriction fragment length polymorphism 
(RFLP) (Van de Walle et al., 2007). Strain $\mathrm{EQ}_{1} 012$ was obtained from Intervet (Heldens et $a l ., 2001)$ and strain V01-3-13 was isolated from a horse with respiratory disease and obtained from the Institut für Virologie in Berlin (kind gift of Dr. K. Borchers).

The EHV-1 isolate 03P37 was isolated from peripheral blood mononuclear cells (PBMC) of a paralytic horse in 2003 and typed as neurovirulent by the Animal Health Trust in the United Kingdom (Nugent et al., 2006). EHV-1 strain RacL11 was isolated in the late 1950s from an aborted foal and exhibits high virulence in the natural host and laboratory animals (Reczko \& Mayr, 1963; Mayr et al., 1968).

\subsection{Inoculation of the nasal mucosal explants}

All explants were inoculated after $24 \mathrm{~h}$ of culture. Inoculation took place by immersion of the explant in $1 \mathrm{ml}$ of inoculum, containing $10^{6.5} \mathrm{TCID}_{50}$ of EHV-1 or EHV-4 for $1 \mathrm{~h}$ at $37^{\circ} \mathrm{C}$ and $5 \% \mathrm{CO}_{2}$. After incubation, explants were washed twice with warm medium and transferred back to their gauze. At several time points post inoculation (pi), explants were collected, embedded in methylcellulose medium (Methocel ${ }^{\circledR} \mathrm{MC}$, Sigma-Aldrich) and frozen at $-70{ }^{\circ} \mathrm{C}$.

Nasal explants of three horses were collected. Of each horse, several explants were made and inoculated with different EHV-1 isolates (03P37, parental RacL11) and EHV-4 isolates (VLS 829, $\mathrm{EQ}_{1}$ 012, V01-3-13), and collected at different time points pi (0, 24, 48 and $\left.72 \mathrm{hpi}\right)$.

\subsection{Plaque analysis and quantification of individual infected cells}

At $0,24,48$ and $72 \mathrm{hpi}$, one hundred consecutive cryosections of $20 \mu \mathrm{m}$ were made of the frozen explants and the cryosections were fixed in methanol for $20 \mathrm{~min}\left(-20{ }^{\circ} \mathrm{C}, 100 \%\right)$. Subsequently, the basement membrane (BM) of the tissues was stained with monoclonal mouse anti-collagen VII antibodies (Sigma-Aldrich), followed by secondary Texas Red ${ }^{\circledR}$ 
142 labeled goat anti-mouse antibodies (Molecular Probes (Invitrogen)). In a second step, viral

143 proteins were stained by incubation with biotinylated equine polyclonal anti-EHV-1 IgG (van

144 der Meulen et al, 2003), followed by streptavidin-FITC ${ }^{\circledR}$ (Molecular Probes (Invitrogen)).

145 This polyclonal antibody against EHV-1 shows cross-reactivity with EHV-4 and was

146 therefore also used for staining of EHV-4. Antibodies were incubated for $1 \mathrm{~h}$ at $37^{\circ} \mathrm{C}$ and 5

$147 \% \mathrm{CO}_{2}$. Finally, cryosections were washed three times in PBS and mounted with glycerin-

148 DABCO (Janssen Chimica, Beerse, Belgium). To reproducibly analyse the replication

149 characteristics of several EHV-1 isolates, we used a system set up by Glorieux et al. (2009)

150 and optimized by Vandekerckhove et al. (2010). Briefly, penetration of the virus through the

151 BM was inspected and virus plaque latitudes were measured in one hundred consecutive

152 cryosections using the Image 1.28 software that is freely available from the National Institute

153 of Mental Health webpage (http://rsb.info.nih.gov/ij/docs/intro.html). Plaque latitude was

154 measured by means of the line tool in ImageJ. Number of plaques and number of individual

155 infected cells below the BM were counted by confocal microscopy (Leica TCS SP2 laser

156 scanning spectral confocal system, Leica Microsystems GmbH, Wetzlar, Germany) and the

157 Leica confocal software.

158

$159 \quad$ 2.6. Statistical analysis

160 The data were processed by the SPSS software (SPSS) for analysis of variance (ANOVA).

161 The data are presented as means + standard deviations. Results with $P$ values of $\leq 0.05$ were

162 considered significant. 


\section{Results}

165

3.1. EHV-4 strains replicate plaquewise in the epithelial cells of respiratory mucosal explants but are severely impaired in infecting mononuclear cells

Replication kinetics of several EHV-4 strains were evaluated in our respiratory nasal mucosal explant system. To this end, nasal explants of three individual horses were inoculated with $10^{6.5} \mathrm{TCID}_{50} / \mathrm{ml}$ of the EHV-4 isolates VLS 829, EQ 1 012, V01-3-13 and of each animal and for every strain used, one explant was examined at each collected time point $(0,24,48$ and 72 hpi).

No significant differences were seen in the results obtained with different EHV-4 strains, and hence, results will not be discussed separately for each strain. In general, viral epithelial plaques were visible starting from 24 hpi (Figure 1A) and their latitudes increased over time (Figure 1B).

These results are similar to what is normally observed upon inoculation of nasal mucosal explants with EHV-1. Indeed, when comparing the replication kinetics of the EHV-4 strains with the replication kinetics of the EHV-1 strains 03P37 and RacL11 (Figure 2), following observations were made. Viral plaques in the epithelium were seen from 24 hpi onwards. In addition, plaque latitude of these epithelial plaques increased over time, with significant differences between the EHV-1 plaque latitudes and the EHV-4 plaque latitudes at all observed time points (Figure 2B). The number of plaques and plaque latitudes increased significantly between 24 and 48 hpi, but no longer between 48 and 72 hpi (Figure 2A).

When evaluating infection below the BM, no individual infected cells were noticed at any observed time point pi for the EHV-4 strains VLS 829 and V01-3-13, and for strain EQ 1012 , only three EHV-4-infected cells were found below the BM in the explant of 1 horse at 72 hpi (Table I). As these individual infected cells below the BM were only noticed very rarely, this implies that there is hardly any passing of virus through the BM via individual infected 
189

190

191

192

193

194

195

196

197

198

199

200

201

202

203

204

205

206

207

208

209

210

211

212

213

immune cells, which is in striking contrast to what is normally observed for EHV-1 strains.

Indeed, upon inoculation with strains 03P37 and RacL11, the presence of single infected cells in the underlying connective tissue was observed from 24 hpi onwards and the number of these single EHV-1-infected cells increased over time with an average of $21 \pm 4.4$ cells at 24 hpi, $135 \pm 58.3$ cells at $48 \mathrm{hpi}$, and $546 \pm 94.3$ cells at 72 hpi for strain $03 \mathrm{P} 37$, and an average of $6 \pm 1.2$ cells at $24 \mathrm{hpi}, 78.7 \pm 20.3$ cells at $48 \mathrm{hpi}$, and $156.3 \pm 16.3$ at 72 hpi for strain RacL11 (Table I). EHV-1 strain 03P37 infected significantly more cells below the BM than EHV-1 strain RacL11.

In conclusion, these experiments indicate that (i) EHV-4 spreads plaquewise in epithelial cells of nasal mucosal explants, similar to EHV-1 albeit to a lesser extent, and (ii) EHV-4, in contrast to EHV-1, has no marked tropism for mononuclear leukocytes as single infected cells were rarely observed below the basement membrane at all time points pi.

\section{Discussion}

The subfamily of the Alphaherpesvirinae is, within the family of the Herpesviridae, an extensive subfamily containing numerous mammal, bird and reptile viruses (Davison et al., 2009). Pseudorabies virus (PRV or Suid herpesvirus 1, SHV-1), bovine herpesvirus 1 (BoHV1), equine herpesvirus $1(\mathrm{EHV}-1)$ and $-4(\mathrm{EHV}-4)$ are clinically and economically the most relevant veterinary mammalian viruses belonging to the alphaherpesvirus subfamily. Although these viruses share many similarities, differences between the viruses become apparent when considering the clinical picture and pathogenesis at the level of the upper respiratory tract (URT). While EHV-1 and EHV-4 cause mild respiratory problems, PRV and BoHV-1 have the possibility to cause severe respiratory disease accompanied by pustular, necrotic lesions that progress to large haemorrhagic and ulcerated areas in the respiratory 
214

215

mucosa (Allen and Bryans, 1986, Crabb and Studdert, 1995; Reed and Toribio, 2004; Nauwynck et al., 2007; Nandi et al., 2009). Besides EHV-1, PRV and BoHV-1 can easily spread through the body via a cell-associated viremia, whereas EHV-4-induced viremia is an exceptional event (Nyaga and McKercher, 1980; Patel et al., 1982; Wang et al., 1988; Nauwynck and Pensaert, 1995; van Maanen, 2002; Patel and Heldens, 2005). These differences can partially be explained by the diverse replication and invasion strategies of these viruses in the respiratory mucosa. By means of respiratory mucosal explants, it was found that PRV and BoHV-1 spread horizontally as well as vertically in a plaquewise manner in the epithelium, and that virus-induced plaques penetrated the BM barrier (Glorieux et al., 2007; Steukers et al., 2010). In contrast, the spread of EHV-1-induced plaques was solely lateral, as plaques never crossed the $\mathrm{BM}$ at any time point pi, implying that the $\mathrm{BM}$ functions as an absolute barrier (Gryspeerdt et al., 2010; Vandekerckhove et al., 2010). However, a marked tropism of EHV-1 for mononuclear leukocytes was observed and EHV-1-infected mononuclear leukocytes were present both in the epithelium and below the BM in the vicinity of virus-induced plaques in vitro but also in vivo (Gryspeerdt et al., 2010; Vandekerckhove et $a l ., 2010)$. Hence, these data suggest that closely related alphaherpesviruses use distinct ways of crossing the BM barrier and invading the respiratory mucosa. In the present study, replication of several EHV-4 strains was assessed for the first time in nasal mucosal explants of the horse. Thereby, it was found that EHV-4-induced virus plaques were present in the epithelium, starting from 24 hours post inoculation (hpi), although the lateral spread of EHV4 was less extensive when compared to EHV-1. This is in accordance with the in vivo situation as respiratory signs following an infection with EHV-4 are less severe when compared to those following an EHV-1 infection (Heldens et al., 2001; Patel et al., 2003; Patel and Heldens, 2005). Remarkably, individual EHV-4-infected cells below the BM were only noticed very rarely and were only present for one of the three strains, implying that 
passing of the virus through the BM via individual infected mononuclear leukocytes is an exceptional event in comparison with EHV-1. Also this observation can be linked to the in vivo pathogenesis, since a cell-associated viremia following an EHV-4-induced respiratory infection is not at all consistent (Patel et al., 1982). This was in agreement with a study on kinetics of EHV-4 viral DNA load in peripheral blood leukocytes (PBL) from foals during a field outbreak of respiratory disease, showing that EHV-4 DNA loads in PBLs were low, which indicates that EHV-4 viremia is rare (Pusterla et al., 2005). Hence, the induction of abortion or nervous system disorders upon EHV-4 infection is also scarce (Patel et al., 1982). Indeed, EHV-4 accounts for only 1 to $16 \%$ of herpesviral-induced abortions (Ostlund, 1993; Whitwell et al., 1995a, b) and apart from a single case report in Europe (Meyer et al., 1987), EHV-4 has not been found in association with herpesviral-induced neurologic disease (Ostlund, 1993). This limited capability of EHV-4, in contrast to EHV-1, to initiate a cellassociated viremia might be due to an inefficient infection of these circulating mononuclear cells. Indeed, it has been previously shown that EHV-4 is incapable of efficiently infecting in vitro cultured peripheral blood mononuclear cells (PBMC) and moreover, it was found by using mutational analysis that an RSD motif, present in EHV-1 gD but not in EHV-4 gD, is an important determinant for proper infection of mononuclear cells in vitro (Van de Walle et al., 2008; Osterrieder and Van de Walle, 2010). As our study indicates that some strains are incapable of infecting nasal mucosal mononuclear cells, while some strains are capable of infecting very few mononuclear cells, this might imply that the latter strains are the ones able to cause abortion or nervous system disorders in the field.

Another interesting observation in our present study was that the EHV-1 strain RacL11 showed a mild infection pattern in mucosal explants when compared to infection patterns obtained upon inoculation with several other EHV-1 strains such as Ab4, NY03 and different Belgian field isolates (Vandekerckhove et al., 2010). Epithelial plaques were smaller in size 
and, when compared to other previously tested EHV-1 strains, only a fraction of individual infected cells below the BM was observed at 72 hpi (Vandekerckhove et al., 2010). This is in agreement with results obtained in in vivo studies comparing the pathogenic potential of EHV-1 strains in the horse. Upon infection with Ab4, horses displayed a significantly longer period of fever, a higher nasal virus excretion and a longer duration of viremia, when compared to RacL11 (Goodman et al., 2007; G. Van de Walle, personal communication). This seems to indicate that RacL11 is an attenuated EHV-1 strain with less virulent potential in the horse than other EHV-1 strains, such as Ab4. In mice however, inoculation with RacL11 does result in severe symptoms such as a dramatic body weight loss within days of infection, a strong inflammatory infiltration in the lungs and even death (von Einem et al., 2007). The murine model is frequently used as an in vivo model for investigation of virological and histological aspects of EHV-induced disease in the horse (Awan et al., 1990; Walker et al., 1999). However, to which extent valid comparisons and extrapolations can be made from mouse to horse remains highly questionable (Walker et al., 1999). Concerning the pathogenesis of equine herpesviruses, we conclude that our in vitro model appears to relate more closely to the in vivo situation in the natural host than the murine model. Indeed, the pathogenesis of an infection with EHV-1 strain RacL11 in the explant model closely resembles the situation in the natural host, whereas the clinical picture in the mouse model is much more dramatic (von Einem et al., 2007). Also, EHV-4 replication in equine explants is similar to the in vivo situation, with a solid replication in epithelial cells but an incapability to infect mononuclear cells, whereas EHV-4 is incapable of infecting murine respiratory mucosa (Awan et al., 1990; Azmi and Field, 1993). This indicates that our in vitro respiratory mucosal explant system is a valuable alternative model to provide novel information on pathogenesis or differences in pathogenic potential of different EHV-4 strains, in addition to the currently existing EHV-1/EHV-4 models. 
290 Despite severe efforts from researchers worldwide, an adequate vaccine preventing the severe 291 EHV-1-induced symptoms such as abortion and equine herpes myeloencephalopathy (EHM) 292 remains to be developed (Patel \& Heldens, 2005; Kydd et al., 2006; Rosas et al., 2006; 293 Brosnahan and Osterrieder, 2009; Pusterla et al., 2009). The effect of the existing vaccines, 294 both inactivated and attenuated, seems to be limited to the alleviation of viral shedding and 295 clinical signs. An adequate protection against viremia, and thus severe EHV-1-induced symptoms such as abortion and EHM, might be reached by impeding the virus to cross the

297

\section{Conclusion}

312 The following conclusions can be drawn from the observations presented in this study. EHV3134 spreads plaquewise in epithelial cells of nasal mucosal explants, similar to EHV-1 albeit to a 
314 lesser extent. Remarkably, and in contrast to EHV-1, the EHV-4 strains in the present study

315 have no marked tropism for mononuclear leukocytes as single EHV-4-infected cells are only 316 rarely observed below the BM at all time points pi. Both these observations can be linked to

317 the in vivo situation since respiratory signs following an infection with EHV-4 are less severe 318 when compared to those following an EHV-1 infection, and since a cell-associated viremia 319 following an EHV-4-induced respiratory infection is not at all consistent, and hence neither is 320 the induction of abortion or nervous system disorders upon EHV-4 infection. The excellent 321 correlation between the in vitro model and the in vivo situation in the horse indicates that our 322 in vitro respiratory mucosal explant system is a valuable tool to provide novel information on 323 pathogenesis or differences in pathogenic potential of different EHV-4 strains.

\section{Conflict of interest statement}

326 None of the authors of this paper has a financial or personal relationship with other people or 327 organisations that could inappropriately influence or bias the content of the paper.

\section{Acknowledgements}

This research was supported by the Institute for the promotion of Innovation through Science and Technology in Flanders (IWT-Vlaanderen). We thank Carine Boone and Chantal Vanmaercke for their excellent technical assistance.

\section{References}

Allen, G.P., Bryans, J.T., 1986. Molecular epizootiology, pathogenesis, and prophylaxis of equine herpesvirus-1 infections. Prog. Vet. Microbiol. Immunol. 2, 78-144. 
Awan, A.R., Chong, Y-C, Field, H.J., 1990. The pathogenesis of equine herpesvirus type 1 in the mouse: a new model for studying host responses to the infection. J. Gen. Virol. 71, $1131-1140$.

Azmi, M., Field, H.J., 1993. Interactions between equine herpesvirus 1 and equine herpesvirus 4: T cell responses in a murine infection model. J. Gen. Virol. 74, 23392345.

Brosnahan, M.M., Osterrieder, N., 2009. Equine Herpesvirus-1: A review and update. In: Mair, T.S., Hutchinson, R.E. (Eds.), Infectious disease of the horse, Equine Veterinary Journal Ltd., Fordham, pp. 41-51.

Crabb, B.S., Studdert, M.J., 1995. Equine herpesvirus 4 (equine rhinopneumonitis virus) and 1 (equine abortion virus). Adv. Virus Res. 45, 153-190.

Davison, A.J., Eberle, R., Ehlers, B., Hayward, G.S., McGeoch, D.J., Minson, A.C., Pellett, P.E., Roizman, B., Studdert, M.J., Thiry, E., 2009. The order Herpesvirales. Arch. Virol. 154, 171-177.

Edington, N., Bridges, C.G., 1990. One way protection between equid herpesvirus 1 and 4 in vivo. Res. Vet. Sci. 48, 235-239.

Glorieux, S., Van den Broeck, W., van der Meulen, K.M., van Reeth, K., Favoreel, H.W., Nauwynck, H.J., 2007. In vitro culture of porcine respiratory nasal mucosa explants for studying the interaction of porcine viruses with the respiratory tract. J. Virol. Methods 142, 105-112.

Glorieux, S., Favoreel, H.W., Meesen, G., de Vos, W., Van den Broeck, W., Nauwynck, H.J., 2009. Different replication characteristics of historical pseudorabies virus strains in porcine respiratory nasal mucosa explants. Vet. Microbiol. 136, 341-346.

Goodman, L.B., Loregian, A., Perkins, G.A., Nugent, J., Buckles, E.L., Mercorelli, B., Kydd, J.H., Palù, G., Smith, K.C., Osterrieder, N., Davis-Poynter, N., 2007. A point mutation 
in a herpesvirus polymerase determines neuropathogenicity. PLoS pathog. 3, 15831592.

Gryspeerdt, A., Vandekerckhove, A.P., Garré, B., Barbé, F., Van de Walle, G.R., Nauwynck, H.J., 2010. Differences in replication kinetics and cell tropism between neurovirulent and non-neurovirulent EHV-1 strains during the acute phase of infection in horses. Vet. Microbiol. 142, 242-253.

Heldens, J.G., Hannant, D., Cullinane, A.A., Prendergast, M.J., Mumford, J.A., Nelly, M., Kydd, J.H., Weststrate, M.W., van den Hoven, R., 2001. Clinival and virological evaluation of the efficacy of an inactivated EHV-1 and EHV-4 whole virus vaccine (Duvaxyn EHV-1,4). Vaccination/challenge experiments in foals and pregnant mares. Vaccine 19, 4307-4317.

Kydd, J.H., Smith, K.C., Hannant, D., Livesay, G.J., Mumford, J.A., 1994. Distribution of equid herpesvirus-1 (EHV-1) in the respiratory tract associated lymphoid tissue: Implications for cellular immunity. Equine Vet. J. 26, 470-473.

Kydd, J.H., Townsend, H.G., Hannant, D., 2006. The equine immune respons to equine herpesvirus-1: the virus and its vaccines. Vet. Immunol. Immunop. 111, 15-30.

Mayr, A., Pette, J., Petzoldt, K., Wagener, K., 1968. Untersuchungen zur Entwicklung eines Lebendimpfstoffes gegen die Rhinopneumonitis (Stutenabort) der Pferde. J. Vet. Med. B $15,406-418$.

Meyer, H., Thein, P., Hübert, P., 1987. Characterization of two equine herpesvirus (EHV) isolates associated with neurological disorders in horses. J. Vet. Med. B 34, 545.

Muylle, S., Simoens, P., Lauwers, H., 1996. Ageing horses by an examination of their incisor teeth: An (im)possible task? Vet. Rec. 138, 295-301.

Nandi, S., Kumar, M., Manohar, M., Chauhan, R.S., 2009. Bovine herpes virus infections in cattle. Anim. Health Res. Rev. 10, 85-98. 
Nauwynck, H.J., Pensaert, M.B., 1995. Cell-free and cell-associated viremia in pigs after oronasal infection with Aujeszky's disease virus. Vet. Microbiol. 43, 307-314.

Nauwynck, H.J., Glorieux, S., Favoreel, H., Pensaert, M., 2007. Cell biological and molecular characteristics of pseudorabies virus infections in cell cultures and in pigs with emphasis on the respiratory tract. Vet. Res. 38, 229-241.

Nugent, J., Birch-Machin, I., Smith, K.C., Mumford, J.A., Swann, Z., Newton, J.R., Bowden, R.J., Allen, G.P., Davis-Poynter, N., 2006. Analysis of equid herpesvirus 1 strain variation reveals a point mutation of the DNA polymerase strongly associated with neurovirulent versus nonneurovirulent disease outbreaks. J. Virol. 80, 4047-4060.

Nyaga, P.N., McKercher, D.G., 1980. Pathogenesis of bovine herpesvirus 1 (BHV-1) infections: interactions of the virus with peripheral bovine blood cellular components. Comp. Immunol. Microb. 2, 587-602.

Osterrieder, N., Van de Walle, G.R., 2010. Pathogenic potential of equine herpesviruses: The importance of the mononuclear cell compartment in disease outcome. Vet. Microbiol. $143,21-28$.

Ostlund, E.N., 1993. The equine herpesviruses. Vet. Clin. N. Am. - Equine 9, 283-294.

Patel, J.R., Edington, N., Mumford, J.A., 1982. Variation in cellular tropism between isolates of equine herpesvirus-1 in foals. Arch. Virol. 74, 41-51.

Patel, J.R., Foldi, J., Bateman, H., Williams, J., Didlick, S., Stark, R., 2003. Equid herpesvirus 1 (EHV-1) live vaccine strain C147: efficacy against respiratory diseases following EHV types 1 and 4 challenges. Vet. Microbiol. 92, 1-17.

Patel, J.R., Heldens, J., 2005. Equine herpesviruses 1 (EHV-1) and 4 (EHV-4) epidemiology, disease and immunoprophylaxis: a brief review. Vet. J. 170, 14-23.

Pusterla, N., Leutenegger, C.M., Wilson, W.D., Watson, J.L., Ferraro, G.L., Madigan, J.E., 2009. Equine herpesvirus-4 kinetics in peripheral blood leukocytes and 
nasopharyngeal secretions in foals using quantitative real-time TaqMan PCR. J. Vet. Diagn. Invest. 17, 578-581.

414 Pusterla, N., Wilson, W.D., Madigan, J.E., Ferraro, G.L., 2009. Equine herpesvirus-1 myeloencephalopathy: A review of recent developments. Vet. J. 180, 279-289.

Reczko, E., Mayr, A., 1963. Uber die feinsruktur eines vom pferd isolierten virus den herpesgruppe. (kurze mitteilung) Arch. Gesamte Virusforsch. 13, 591-593.

Reed, S.M., Toribio, R.E., 2004. Equine herpesvirus 1 and 4. Vet. Clin. N. Am. - Equine 20, $631-642$.

Rosas, C.T., Goodman, L.B., von Einem, J., Osterrieder, N., 2006. Equine herpesvirus type 1 modified live virus vaccines: quo vaditis? Expert Rev. Vaccines 5, 119-131.

Sabine, M., Robertson, G.R., Whalley, J.M., 1981. Differentiation of sub-types of equine herpesvirus 1 by restriction endonuclease analysis. Aust. Vet. J. 57, 148-149.

Smith, K.C., Mumford, J.A., Lakhani, K., 1996. A comparison of equid herpesvirus-1 (EHV1) vascular lesions in the early versus late pregnant equine uterus. J. Comp. Pathol. 114, 231-247.

Smith, K.C., Borchers, K., 2001. A study of the pathogenesis of equid herpesvirus-1 (EHV-1) abortion by DNA in-situ hybridization. J. Comp. Pathol. 125, 304-310.

Steukers, L., Vandekerckhove, A.P., Van den Broeck, W., Glorieux, S., Nauwynck, H.J., 2010. Kinetics of BoHV-1 dissemination in an in vitro culture of bovine upper respiratory tract mucosa explants. ILAR e-Journal, in press.

432 Studdert, M.J.,Blackney, M.H., 1979. Equine herpesviruses: on the differentiation of respiratory from foetal strains of type 1. Aust. Vet. J. 55, 488-492.

434 Studdert, M.J., Simpson, T., Roizman, B., 1981. Differentiation of respiratory and abortigenic isolates of equine herpesvirus 1 by restriction endonucleases. Science 214, 562-564. 
Telford, E.A., Watson, M.S., Perry, J., Cullinane, A.A., Davison, A.J., 1998. The DNA sequence of equine herpesvirus-4. J. Gen. Virol. 79, 1197-1203.

Trapp, S., von Einem, J., Hofmann, H., Köstler, J., Wild, J., Wagner, R., Beer, M., Osterrieder, N., 2005. Potential of equine herpesvirus 1 as a vector for immunization. J. Virol. 79, 5445-5454.

Vandekerckhove, A., Glorieux, S., Van den Broeck, W., Gryspeerdt, A., van der Meulen, K.M., Nauwynck, H.J., 2009. In vitro culture of equine respiratory mucosa explants. Vet. J. 181, 280-287.

Vandekerckhove, A., Glorieux, S., Gryspeerdt, A.C., Steukers, L., Duchateau, L., Osterrieder, N., Van de Walle, G.R., Nauwynck, H.J., 2010. Replication kinetics of neurovirulent versus non-neurovirulent equine herpesvirus type 1 strains in equine nasal mucosal explants. J. Gen. Virol. 91, 2019-2028.

van der Meulen, K.M., Vercauteren, G., Nauwynck, H.J., Pensaert, M.B., 2003. A local epidemic of equine herpesvirus 1-induced neurological disorders in Belgium. Vlaams Diergen. Tijds. 72, 366-372.

Van de Walle, G.R., May, M.L., Woraporn, S., von Einem, J., Osterrieder, N., 2007. Herpesvirus chemokine-binding glycoprotein $\mathrm{G}(\mathrm{gG})$ efficiently inhibits neutrophil chemotaxis in vitro and in vivo. J. Immunol. 179, 4161-4169.

Van de Walle, G.R., Peters, S.T., VanderVen, B.C., O’Callaghan, D.J., Osterrieder, N., 2008. Equine herpesvirus 1 entry via endocytosis is facilitated by alphaV integrins and an RSD motif in glycoprotein D. J. Virol. 82, 11859-11868.

Van Maanen, C., 2002. Equine herpesvirus 1 and 4 infections: an update. Vet. Q. 24, 58-78.

Von Einem, J., Smith, P.M., Van de Walle, G.R., O’Callaghan, D.J., Osterrieder, N., 2007. In vitro and in vivo characterization of equine herpesvirus type 1 (EHV-1) mutants devoid of the viral chemokine-binding glycoprotein $\mathrm{G}$ (gG). Virology 362, 151-162. 
461

462

463

464

465

466

467 13, 53-72. 264.

Walker, C., Love, D.N., Whalley, J.M., 1999. Comparison of the pathogenesis of acute equine herpesvirus 1 (EHV-1) infection in the horse and the mouse model : a review. Vet. Microbiol. 68, 3-13.

Wang, F.-I., Pang, V.F., Hahn, E.C., 1988. Flow cytometric analysis of porcine peripheral blood leukocytes infected with Aujeszky's disease virus. J. Leukocyte Biol. 43, 256-

Whitwell, K.E., Bowen, J.M., Hannant, D., 1995a. The search for antibody to equine herpesvirus-1 in equine fetuses. In: Nakajima, W., Plowright, W. (Eds), Proceedings of the Seventh International Conference on Equine Infectious Diseases, R\&W Publications, Newmarket, pp. 339-340.

Whitwell, K.E., Smith, K., Sinclair, R., Mumford, J., 1995b. Fetal lesions in spontaneous EHV-4 abortions in mares. In: Plowright, W., Nakajima, W. (Eds), Proceedings of the Seventh International Conference on Equine Infectious Diseases, R\&W Publications, Newmarket, pp. 354.

Wilson, W.D., 1997. Equine herpesvirus 1 myeloencephalopathy. Vet. Clin. N. Am.- Equine 
478

479

480

481

482

483

484

485

486

487

488

489

490

491

492

493

494

495

496

497

498

499

500

\section{Figure legends}

Figure 1. Evolution of plaque formation in the epithelial cells of nasal explants for several EHV-4 isolates (VLS 829, EQ1 012, V01-3-13). Equine respiratory mucosal explants were inoculated $\left(10^{6.5} \mathrm{TCID}_{50} / \mathrm{ml}\right.$ of EHV-4) and at $0,24,48$ and 72 hours post inoculation (hpi), explants were collected. One hundred consecutive sections were made and analysed. (A) Number of plaques was determined at 24, 48 and 72 hpi. (B) Plaque latitudes were always measured for 10 plaques at every time point and for every horse. All data represent means + SD of triplicate independent experiment.

Figure 2. Evolution of plaque formation in the epithelial cells of nasal explants for EHV-

1 and EHV-4. Equine respiratory mucosal explants were inoculated $\left(10^{6.5} \mathrm{TCID}_{50} / \mathrm{ml}\right.$ of EHV) and at 0, 24, 48 and 72 hours post inoculation (hpi), explants were collected. (A) Number of plaques was determined at 24, 48 and 72 hpi. (B) Plaque latitudes were always measured for 10 plaques at every time point and for every horse. The values for EHV-1 are the average of the 2 isolates $03 \mathrm{P} 37$ and RacL11, the values for EHV-4 are the average of the 3 isolates VLS 829, EQ 012 and V01-3-13. All data shown represent means + SD of triplicate independent experiments and $P$ values for statistical significance are given for each strain. Asterisks indicate statistically significant differences $(P \leq 0.05)$. Representative confocal photomicrographs are given, illustrating viral plaques in the epithelium (green) at $72 \mathrm{hpi}$ (objective 20x) for EHV-1 isolate 03P37 (C) and EHV-4 isolate VLS 829 (D). Single EHV-1infected cells are clearly visible in the connective tissue below the basement membrane (red) for EHV-1 isolate 03P37 (c). For EHV-4 isolate VLS 829 (d), single EHV-4-infected cells in the connective tissue are absent. 
Table 1. Quantification of EHV-infected cells below the BM

\begin{tabular}{lcccc}
\hline & Virus designation & \multicolumn{2}{c}{ No of EHV-infected cells below the BM at .. hpi / } \\
& & \multicolumn{3}{c}{100 cryosections } \\
\cline { 3 - 5 } & VLS 829 & $0 \pm 0.0$ & $0 \pm 0.0$ & $0 \pm 0.0$ \\
\hline EHV-4 & EQ1 012 & $0 \pm 0.0$ & $0 \pm 0.0$ & $1 \pm 1.7$ \\
EHV-4 & V01-3-13 & $0 \pm 0.0$ & $0 \pm 0.0$ & $0 \pm 0.0$ \\
EHV-4 & 03P37 & $21 \pm 4.4$ & $135 \pm 58.3$ & $546 \pm 94.3$ \\
EHV-1 & RacL11 & $6 \pm 1.2$ & $78.7 \pm 20.3$ & $156.3 \pm 16.3$ \\
\hline
\end{tabular}

503 
A

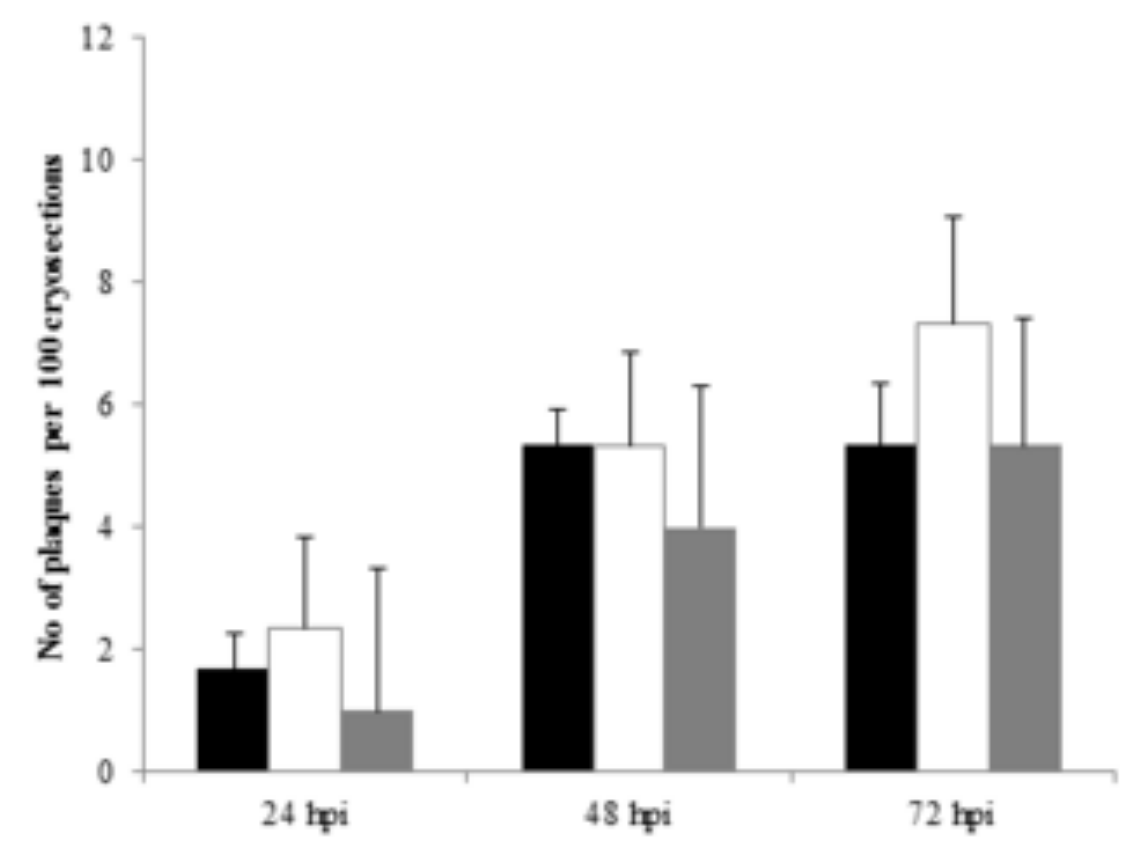

B

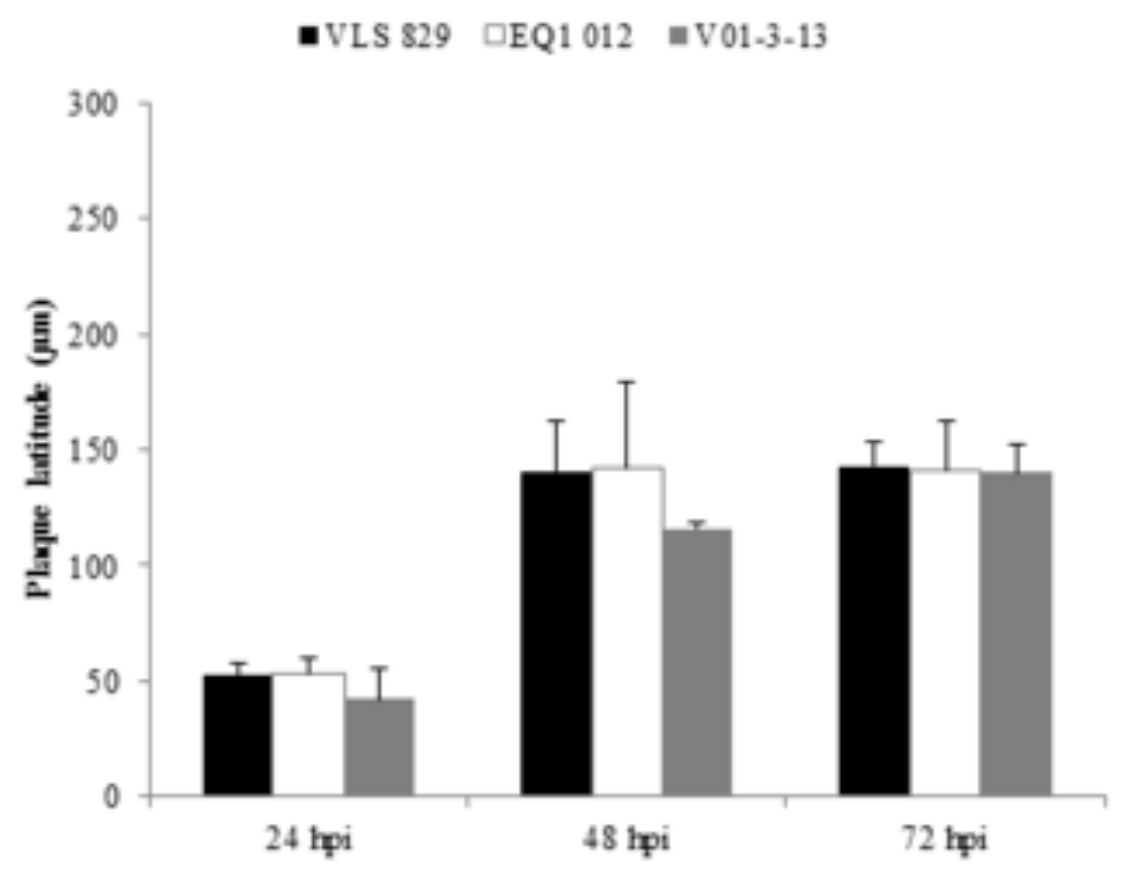

Figure 1. Vandekerckhove et al. 
Click here to download high resolution image

A

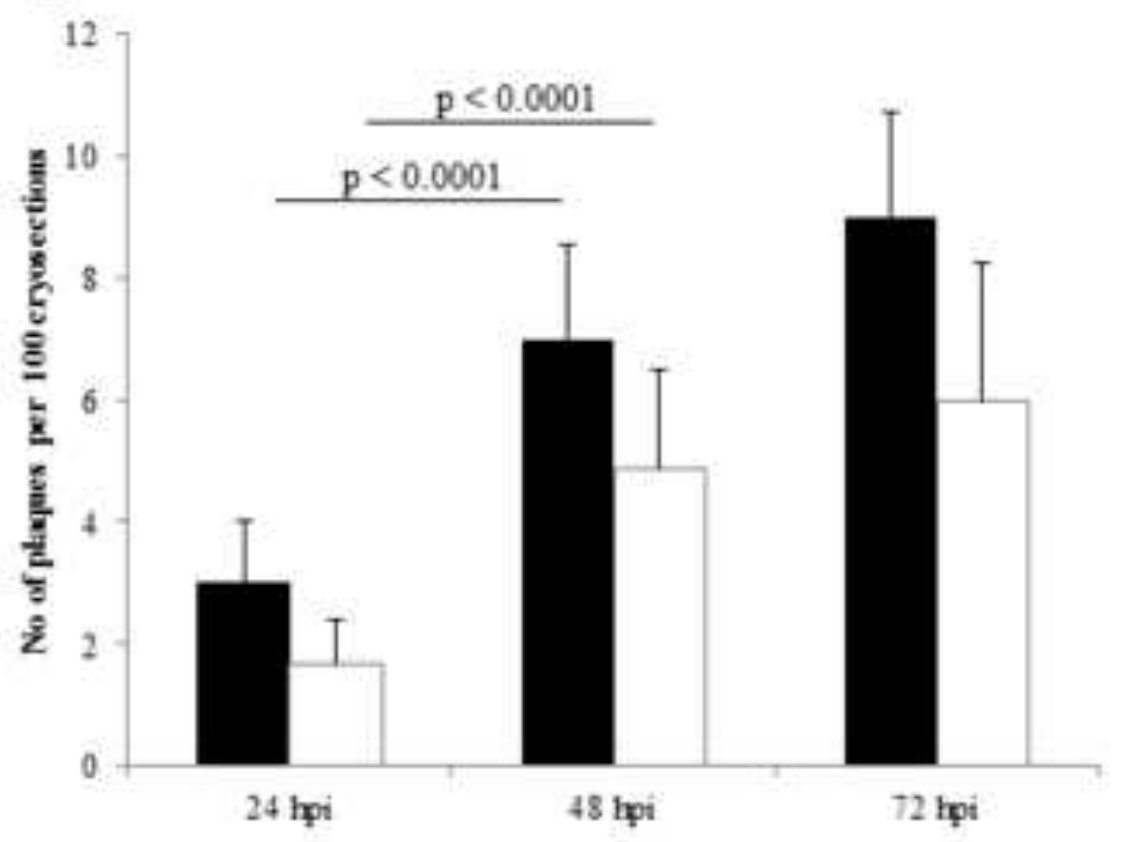

B

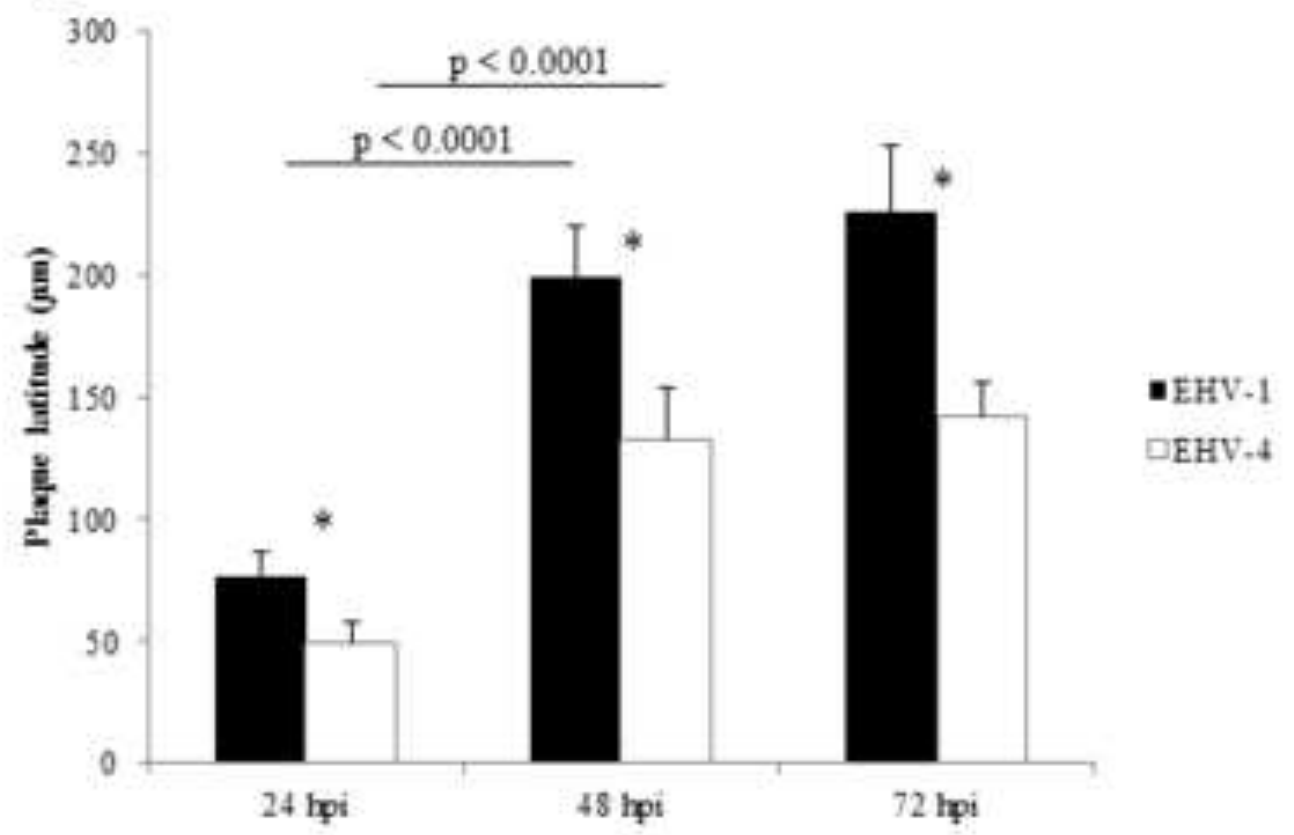

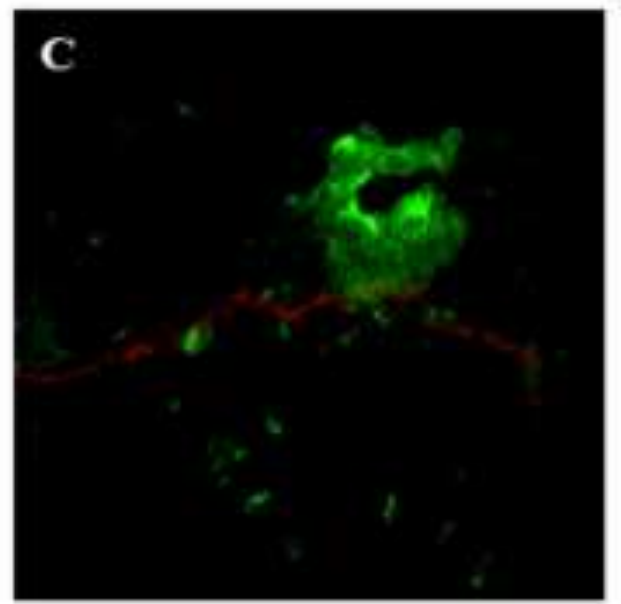

D

Figure 2. Vandekerckhove et al. 